\title{
STATISTICAL ANALYSIS TO IDENTIFY THE MAIN PARAMETERS TO EFFECTING WWQI OF SEWAGE TREATMENT PLANT AND PREDICTING BOD
}

\author{
A.K.Khambete ${ }^{1}$, R.A.Christian ${ }^{1}$ \\ ${ }^{1,2}$ Associate Professor, Faculty of civil Eng. S.V. National Institute of Technology, Surat
}

\begin{abstract}
The present study was conducted to determine the wastewater quality index and to study statistical interrelationships amongst different parameters. The equation was developed to predict BOD and WWQI. A number of water quality physicochemical parameters were estimated quantitatively in wastewater samples following methods and procedures as per governing authority guidelines. Wastewater Quality Index (WWQI) is regarded as one of the most effective way to communicate wastewater quality in a collective way regarding wastewater quality parameters. The WWQI of wastewater samples was calculated with fuzzy MCDM methodology. The wastewater quality index for treated wastewater was evaluated considering eight parameters subscribed by Gujarat Pollution control Board (GPCB), a governing authority for environmental monitoring in Gujarat State, India. Considerable uncertainties are involved in the process of defining the treated wastewater quality for specific usage, like irrigation, reuse, etc.
\end{abstract}

The paper presents modeling of cognitive uncertainty in the field data, while dealing with these systems recourse to fuzzy logic. Also a statistical study is done to identify the main affecting variables to the WWQI. The Statistical Regression Analysis has been found to be highly useful tool for correlating different parameters. Correlation Analysis of the data suggests that TDS, SS, BOD, COD, O\&G and $\mathrm{Cl}$ are significantly correlated with WWQI and DO of wastewater. The estimated BOD from independent variance DO for maximum, minimum and average is $25.35 \mathrm{mg} / \mathrm{L}, 2.65 \mathrm{mg} / \mathrm{L}$ and $13.56 \mathrm{mg} / \mathrm{L}$ respectively. While estimated WWQI from independent variance DO for maximum, minimum and average is 0.6212, 0.3074 and 0.4581 respectively. Out of eight parameters, TDS-BOD, TDS-COD, TDS$C l$, SS-BOD, SS-COD, and BOD-COD are significantly correlated. Present study shows that WWQI is influenced by BOD, COD, SS and TDS.

Keywords: Wastewater quality, Uncertainty, fuzzy set theory, correlation, Regression.

\section{INTRODUCTION}

As urban and industrial development increases, the quality of waste generated also increases (Mohmmed, 2006). Discharge of untreated waste in to surface waters, such as rivers, lacks and seas, determine the contamination of waters for human purposes (Gabrieli et al., 1997). The treatment objectives were concerned with the removal of suspended floatable material, the treatment of biodegradable organics and elimination of pathogenic organisms ( Jamrah, 1999). So the wastewater or sewage treatment is one such alternative, where in many processes are designed and operated in order to copy the natural treatment process to reduce contaminant load to a level that environment can hold ( Ravi kumar, 2010). The WQI is presenting a cumulatively derived numerical expression defining a certain level of water quality (Bordelo, 2006). Water quality indices aim at giving a single value to the water quality of a source reducing great amount of parameters into a simpler expression and enabling easy interpretation of monitoring data (Bharti, 2011). In other words, WQI summarizes large amounts of water quality data into simple terms (e.g., excellent, good, bad, etc.) for reporting to management and the public in a consistent manner. Various researchers have considered similar approaches which brought changes to the methodology depending on the usage and parameters under consideration. Prati et al. (1971) considered 13 different parameters of equal weight in their system. And water quality index that is able to rapidly assess whether an effluent-properly polished-is adequate for agricultural or recreational purposes could be of great help to managers and decision makers in water resources planning as well as for comparing different wastewater treatment sequences (Verlicchi et al., 2012).

Also there is a need to define one common parameter which could determine the overall efficiency of plant in terms of physical, biochemical and microbiological removal efficiencies (Jamwal 2009). A new fuzzy approach initiated by Zadeh 1965, has been adopted. i.e. Wastewater Quality Index (WWQI), which represent the wastewater quality in terms of 
numeric i.e. 0 to 1 . Developing the WWQI on the line of WQI is expected to be more practical in implementation and can become effective decision making tool for authority.

The Multi Criteria Decision Making (MCDM) method is applied to determine the WWQI at Surat WWTP, and maximum, minimum and average values for WWQI were found out, which are $0.6284,0.2835$ and 0.4433 respectively. Once, WWQI was calculated the correlation between WWQI and all the parameters was calculated. Factor Analysis (FA) was adopted to assist the interpretation of elemental data (Akobundu 2007). So, an attempt has been made to find out the solution of this problem by developing WWQI and computing correlation and regression equations to assess the wastewater quality of an treated wastewater on the basis of few parameters.

For this SPSS tool was used. From this analysis, parameters significantly affecting WWQI were found out (TDS, COD, and DO etc.). At last, considering significant parameters, a regression equation was developed using SPSS.

This equation was used to calculate WWQI once again. Finally, the results obtained from both MCDM method and further the regression equations were compared and the regression equation was developed to estimate WWQI and BOD from measured value of DO.

\section{WATER QUALITY INDEX BY MCDM METHOD}

Due to fluctuations in organic and hydraulic loading in a wastewater treatment plant, the application of fuzzy logic, using linguistic variables gave a better description of performance parameters. The number of criteria in multicriteria decision making is virtually assumed to be finite (Evangelos,2000 and Klir,1998). Balteiro and Romero (2004) utilized a sustainability aggregating model in search an index to natural systems sustainability. Chen et al. (2011) utilized fuzzy MCDM approach and fuzzy AHP for selecting the best environment-watershed plan in Taiwan.

\subsection{Multi Criteria Decision Making (MCDM) approach for Determination of the WWQI}

The approach for the evaluating WWQI of treated wastewater is based on somewhat analogous to the procedure suggested by Singh and Tong (2005). The chart portrays an overview of the fuzzy decision framework for evaluating the MPAI, which is self-explanatory Figure 1.The first step is identification of environmental experts.

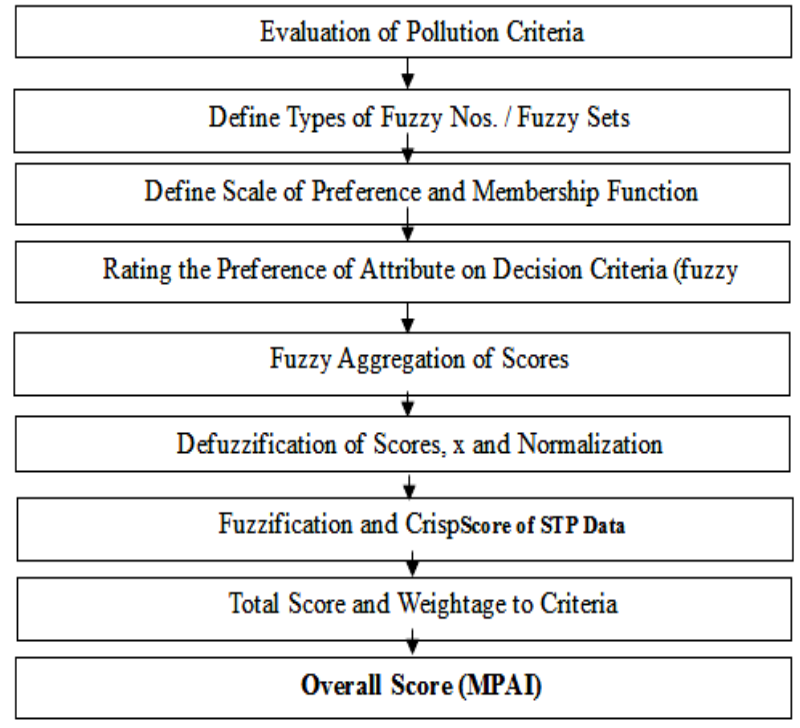

Fig 1:Step Involved in a MCDM ModelAssignimportance weightage to the sub criteria of wastewater.

Weight for each of the sub criterion is developed by normalized weight method by consulting the environmental experts. In the present study, five fuzzy numbers are selected to describe the level of performance on decision criteria in evaluation of MPAI. Five linguistic variables are used because it is convenient for an expert to distinguish subjectively between them.

The approach for developing MPAI was based on strength of different parameters is somewhat analogous to the procedure suggested by Singh and Tong (2005). Linguistic variables assigned for the study were five; Highly Significant (HS), Significant (S), Average Significant (AV), Low Significant (LS), and Not Significant (NS).Each were defined with four fuzzy numbers average of the numbers assigned by experts presented in Table below.

Table 1: Fuzzy numbers associated with the corresponding Linguistic Variables.

\begin{tabular}{|l|l|}
\hline Linguistic variables & Fuzzy Number \\
\hline Highly Significant (HS) & $(0.7,0.8,0.9,1.0)$ \\
\hline Significant (S) & $(0.5,0.6,0.7,0.8)$ \\
\hline Average Significant(AS) & $(0.3,0.40 .5,0.6)$ \\
\hline Low Significant (LS) & $(0.1,0.2,0.3,0.4)$ \\
\hline Not Significant (NS) & $(0.0,0.0,0.1,0.2)$ \\
\hline
\end{tabular}

The graphical presentation of fuzzy numbers for the linguistic variables used by seven environmental experts to develop weightage for each criterion is shown in Figure2. 


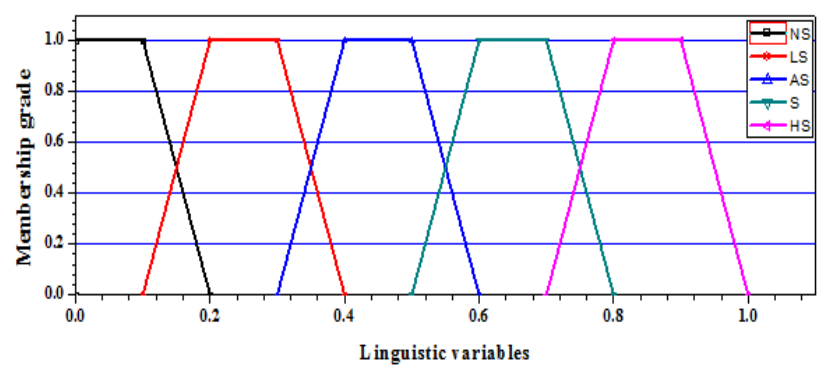

Fig 2: Graphical representation of trapezoidal membership function

The weightage factors are computed for eight sub criteria (parameters) of wastewater for raw and treated wastewater. On the basis of the experts' opinion (linguistic variable) or perception, a fuzzy decision matrix for the sub criteria of wastewater is computed.

Weights are evaluated using the equation given below. The average fuzzy numbers for all the environmental experts' opinion can be expressed as

$$
\begin{gathered}
A^{k} i j=(1 / p)\left(a_{i 1}^{k}+a_{i 2}^{k}+a_{i 3}^{k}+\cdots \ldots .+a_{p}^{k}\right) \text { for } j \\
=1,2, \ldots \ldots, p
\end{gathered}
$$

Where akij be the fuzzy number (weight) assigned to an alternative $\mathrm{Ai}$ by $\mathrm{DMj}$ (Decision Maker i) for the decision criteria $\mathrm{Ck}$ and $\mathrm{p}$ is the number of environment experts involved in the evaluation process. The linguistic variables as assigned by the experts are converted to fuzzy numbers used in the above expressions through Figure. Now, the defuzzified values for the sub-criteria are obtained by the equation below; (Kaufmann; 1991).

$$
\mathrm{e}=\mathrm{X} 1+\mathrm{X} 2+\mathrm{X} 3+\mathrm{X} 4 / 4
$$

The normalized weight for each sub criterion of raw and treated wastewater is obtained by dividing the scores of each sub criterion ( $C_{i j}$ ) by the total of all sub-criterion $\left(\sum C_{i j}\right)$. The next step is to convert the parametric values of raw and treated wastewater to the fuzzy numbers (membership functions) based on the specified statutory norms. Using simple additive weighing method (Hwang and Yoon, 1981), the overall score (OS) in terms of MPAI for raw and treated wastewater criteria can be calculated using following equation.

$$
\mathrm{OS}=\sum\left(\mathrm{X}_{\mathrm{k}} \otimes \mathrm{W}\left(\mathrm{C}_{\mathrm{k}}\right)\right) \text { for } \mathrm{k}=1,2, . . n
$$

Where, ${ }^{W}\left(C_{k}\right)$ =weight (importance value) of the sub criterion $\mathrm{k}$ and

$$
\begin{aligned}
& X_{k}=\text { crisp score (defuzzified value) of treated data against } \\
& \text { the sub criterion } \mathrm{k} .
\end{aligned}
$$

\subsection{Stastical Analysis}

To evaluate wastewater quality from a large number of ample each having number of parameters is difficult. To analyze the water quality, different approaches like statistical analysis of individual parameter, multi- stressor water quality indices ect. have been considered (Venkatesha, 2010). Statistical analysis are generally used to identify the calculated WWQI is appropriate or not. For this purpose Correlation Analysis and Multiple Linear Regression analysis were performed.

Correlation Analysis: Correlation is a measure of degree of linear relationship between two variables. It expresses the extent to which two variables vary together in same directions or opposite directions. Correlation coefficients reveal the magnitude and direction of the relationships. A correlation has value ranging from -1 to 1 .Values that are closer to the absolute value 1 indicate that there is a strong positive linear relationship between the variables being correlated, whereas values closer to 0 indicate that there is no liner relationship between two variables under study. Below table 5 shows the correlation between different parameters, which are, applied to evaluate WWQI for treated wastewater. Correlation between different parameters was found out by Florence P. et al(2010) for Water Quality Index and Correlation Study at YercaudTaluk, Salem, Tamil Nadu, India. Also, correlation analysis for lower Maniar Reservoir was carried out by Thirupathaiah M. et. Al.(2012)

Multiple Linear Regression Analysis: It is one of the very important statistical tools which are used in almost all fields of sciences. According to Rastogi, 2011, the Statistical Regression Analysis has been found to be highly useful tool for correlating different parameters. This has twofold advantages. First with the help of correlation analysis it is easy to find out interrelationship between different parameters and also the main parameters affecting the WWQI can be easily figured out. Later with the help of the regression equation WWQI was calculated again and the degree of match is checked. With help of this one can easily eliminate tedious laboratory work of determining all parameters and can carry out its work only with the parameters that are significantly correlated in the regression equation. In regression analysis there are two types of variables. The variable whose value is influenced is called dependent variable and the variables which influence the dependent variable are called explanatory (regressors) variables. And the model equation is:

$$
\begin{gathered}
\mathrm{Y}=\beta 0+\beta 1 \mathrm{X} 1+\beta 2 \mathrm{X} 2+\beta 3 \mathrm{X} 3+\beta 4 \mathrm{X} 4+\beta 5 \mathrm{X} 5+\beta 6 \mathrm{X} 6+ \\
\beta 7 \mathrm{X} 7+\beta 8 \mathrm{X} 8+\mathrm{e}
\end{gathered}
$$

This model should be free from (as assumptions of applying this criteria), Multicolinearity (regressors are correlated), 
Heteroscedasticity (error variance is nonconstant), and Autocorrelation (error terms are correlated).

In this study WWQI is considered as dependent variable and parameters are considered as explanatory variables. Chenini et al(2009) have successfully applied multiple linear regression for Evaluation of ground water quality. Rene et. al.(2008) has also applied regression equation for prediction of water quality indices.

\section{MATERIALS \& METHODOLOGY}

\subsection{Site Selection}

As the study is concerned with the development of WWQI for the treated wastewaters. All the samples were collected from Anjana Treatment Plant located in Surat city itself. All the samples were collected at fix time i.e. at $1 \mathrm{PM}$ to $1.30 \mathrm{PM}$ for a time period of 1 year.

\subsection{Sampling Procedure}

For sampling, the procedure described in Standard Methods and IS 3025 was adopted. DO fixation was performed at the location itself by adding Manganese Sulfate and Alkaline KI solution. For other physico - chemical parameters, samples were collected in 1 liter plastic bottles. Samples were collected in container rinsed with detergents, nitric acid and finally with distilled water. These plastic bottles were placed in ice box to maintain the temperature during travelling periods of sampling.

\subsection{Sample Analysis}

The collected water samples are analyzed for eight different parameters including Temperature, Total dissolved solids (TDS), Suspended solids (SS), Biochemical demand (BOD), Chemical oxygen demand (COD), Oil and grease (O\&G),pH and Chlorides $(\mathrm{Cl})$. All the analyses are carried out as per the guidelines provided in Standard Methods and IS: 3025 (1964).Temperature, DO and $\mathrm{pH}$ were measured at the timeof sample collation.

\section{RESULTS AND DISCUSSION}

Constant monitoring of all the parameters described by CPCB was carried out weekly throughout the year 2011.maximum, minimum and average values of the analyzed data is summarized in Table 2. As the treated wastewater was chlorinated before discharge the FC and FS are omitted as the wastewater was chlorinated before final discharge in to river Tapi. Out of measured nine parameters total eight parameters, except DO were considered to develop WWQI (Table3).

Table 2Minimum, maximum and average Data at Anjana STP

\begin{tabular}{|l|c|c|c|c|c|c|c|c|c|c|}
\hline Parameters & Temp. & TDS & \multicolumn{1}{c|}{ SS } & BOD & COD & O \& G & Cl & pH & DO \\
\hline \multicolumn{8}{|c|}{ Treated Wastewater } \\
\hline Discharge Limits & $\mathbf{4 0}$ & $\mathbf{2 1 0 0}$ & $\mathbf{1 0 0}$ & $\mathbf{3 0}$ & $\mathbf{1 0 0}$ & $\mathbf{1 0}$ & $\mathbf{6 0 0}$ & $\mathbf{6 . 5 - 8 . 5}$ & - \\
\hline Max & 33.80 & 792.00 & 40.00 & 23.00 & 128.00 & 0.80 & 360.00 & 8.05 & 0.74 \\
\hline Min & 24.50 & 634.00 & 6.00 & 5.00 & 32.00 & 0.10 & 280.00 & 7.49 & 5.34 \\
\hline Average & 28.90 & 732.07 & 22.14 & 12.28 & 67.81 & 0.41 & 317.93 & 7.70 & 3.13 \\
\hline Weights & 0.108 & 0.117 & 0.141 & 0.166 & 0.154 & 0.08 & 0.141 & 0.092 & - \\
\hline \multicolumn{8}{|c|}{ Membership Grade $\mathbf{X}_{\mathbf{k}}$} \\
\hline Max & 0.8450 & 0.3771 & 0.4000 & 0.7667 & 1.0000 & 0.0800 & 0.6000 & 0.6999 \\
\hline Min & 0.6125 & 0.3019 & 0.0600 & 0.1667 & 0.3200 & 0.0100 & 0.4667 & 0.3266 \\
\hline Average & 0.7225 & 0.3486 & 0.2214 & 0.4093 & 0.6781 & 0.0410 & 0.5299 & 0.4666 & \\
\hline
\end{tabular}

Note: Except Temperature and $\mathrm{pH}$ all parameters are in $\mathrm{mg} / \mathrm{L}$

Table 3 Minimum, maximum and average values for WWQI by MCDM method and regression equation

\begin{tabular}{|l|c|c|c|}
\hline Data & WWQI by MCDM & $\begin{array}{c}\text { WWQI by regression equation (With 6 } \\
\text { paramters) }\end{array}$ & $\begin{array}{c}\text { WWQI by regression equation (With 5 } \\
\text { parameters) }\end{array}$ \\
\hline Max & 0.6284 & 0.5711 & 0.6172 \\
\hline Min & 0.2835 & 0.2992 & 0.3059 \\
\hline Average & 0.4433 & 0.4241 & 0.4465 \\
\hline
\end{tabular}

Then with the help of Pearson Correlation (Table 4)

statistically significantly correlated variables were identified. 
IJRET: International Journal of Research in Engineering and Technology eISSN: 2319-1163 | pISSN: 2321-7308

Table 4 Pearson Correlation Coefficients showing relation between all the parameters

\begin{tabular}{|c|c|c|c|c|c|c|c|c|c|c|}
\hline & Temp & TDS & SS & BOD & COD & O\&G & Cl & pH & DO & WWQI \\
\hline Temp & 1 & & & & & & & & & \\
\hline TDS & $.989^{* * *}$ & 1 & & & & & & & & \\
\hline SS & $-.522^{* * *}$ & $-.513^{* * *}$ & 1 & & & & & & & \\
\hline BOD & $-.945^{\text {** }}$ & $-.953^{* *}$ & $.584^{* *}$ & 1 & & & & & & \\
\hline COD & $.862^{* *}$ & $.887^{* *}$ & $-.245^{* *}$ & $-.806^{* *}$ & 1 & & & & & \\
\hline OG & $-.985^{* *}$ & $-.996^{* *}$ & $.524^{* *}$ & $.955^{* *}$ & $-.887^{* *}$ & 1 & & & & \\
\hline $\mathrm{Cl}$ & $.991^{* *}$ & $.997^{* *}$ & $-.509^{* *}$ & $-.947^{* *}$ & $.885^{* *}$ & $-.991^{* *}$ & 1 & & & \\
\hline pH & $-.887^{* *}$ & $-.897^{* *}$ & $.517^{* *}$ & $.970^{* * *}$ & $-.797^{* *}$ & $.895^{* *}$ & $-.893^{* *}$ & 1 & & \\
\hline DO & $-.985^{* * *}$ & $-.996^{* * *}$ & $.522^{* * *}$ & $.958^{* * *}$ & $-.888^{* * *}$ & $1.000^{* * *}$ & $-.991^{* * *}$ & $.899^{* * *}$ & 1 & \\
\hline WWQI & .056 & $.287^{* * *}$ & $.720^{* *}$ & $.920^{* * *}$ & $.893^{* * *}$ & .089 & $.321^{* * *}$ & .194 & $-.984^{* *}$ & 1 \\
\hline
\end{tabular}

Out of eight parameters, Out of eight parameters, TDS-SS, TDS-BOD, TDS-COD, TDS-OG, TDS-pH, TDS-DO, SSBOD, SS-COD, SS-OG, SS-Cl, SS-pH, SS-DO, BOD-COD, BOD-OG, BOD-Cl, BOD-pH, BOD-DO, COD-OG, COD-Cl, COD-pH, COD-DO, OG-Cl, OG-pH, OG-DO, Cl-pH, Cl-DO, $\mathrm{pH}-\mathrm{DO}$ are found to be significantly correlated with each other (Table 4). Also it was found that WWQI is significantly correlated with TDS, SS, BOD, COD, Cl and DO which means that out of these nine parameters, only Six parameters are responsible for the deviation or change in the values of WWQI. Now as our main motive is to check the WWQI is correctly drawn or not, we go for regression. From Table 5, unstandardized coefficients for the equation constant, TDS,
SS, BOD, COD, Chloride and DO as 0.456, 0.0000103, $0.000451,0.002448,0.000530,0.000128$, and -0.0412 respectively. These coefficients were replaced with the coefficients of equation 4 and $\mathrm{Y}$ predicted is presented in equation 2. Table 6 shows that the model fit with $98.5 \%$ of accuracy.

Y Estimated $=0.456+0.0000103 \mathrm{X} 1+0.000451 \mathrm{X} 2+$ $0.002448 \mathrm{X} 3+0.000530 \mathrm{X} 4+0.000128 \mathrm{X} 5-0.0412 \mathrm{X} 6$

Where $\mathrm{Y}=\mathrm{WWQI}, \mathrm{X} 1=\mathrm{TDS}, \mathrm{X} 2=\mathrm{SS}, \mathrm{X} 3=\mathrm{BOD}, \mathrm{X} 4=$ $\mathrm{COD}, \mathrm{X} 5=\mathrm{Cl}$, and $\mathrm{X} 6=\mathrm{DO}$

Table 5: Coefficients for regression analysis (Model 1)

\begin{tabular}{|c|c|c|c|c|}
\hline & Coefficients & Standard Error & $t$ Stat & Significance \\
\hline Constant & 0.456091134 & 0.029309116 & 15.56140879 & $6.45896 \mathrm{E}-26$ \\
\hline TDS & $1.03817 \mathrm{E}-05$ & $3.97293 \mathrm{E}-05$ & 0.261309917 & 0.794525072 \\
\hline SS & 0.000451482 & 0.000158837 & 2.842434083 & 0.005679048 \\
\hline BOD & 0.002448483 & 0.000387202 & 6.323524967 & $1.36726 \mathrm{E}-08$ \\
\hline COD & 0.000530319 & $7.9732 \mathrm{E}-05$ & 6.651263435 & $3.29148 \mathrm{E}-09$ \\
\hline Cl & 0.000128486 & $6.10444 \mathrm{E}-05$ & 2.104788562 & 0.038448341 \\
\hline DO & -0.041153394 & 0.003067748 & -13.41485266 & $3.58124 \mathrm{E}-22$ \\
\hline
\end{tabular}

Table 6: Model Summary (Model 1)

\begin{tabular}{|c|c|c|c|c|c|}
\hline Model & $\mathrm{R}$ & R Square & Adjusted R Square & Std. Error of the Estimate & Durbin-Watson \\
\hline 1 & .993 & .986 & .985 & .00642 & 1.937 \\
\hline
\end{tabular}


Table 7: ANOVA (Model 1)

\begin{tabular}{|c|l|c|c|c|c|c|}
\hline \multicolumn{2}{|c|}{ Model } & Sum of Squares & df & Mean Square & F & Sig. \\
\hline \multirow{3}{*}{1} & Regression & .240 & 6 & .040 & 972.248 & .000 \\
\cline { 2 - 7 } & Residual & .003 & 80 & .000 & & \\
\cline { 2 - 7 } & Total & .244 & 86 & & & \\
\hline
\end{tabular}

This model is fitted significantly as $\mathrm{F}=972.248$ (Sig F: 0.000) (Table 7), also root mean square error (RMSE) is 0.000 . This model is not having problem of auto correlation as DurbinWatson test statistic is 1.937 which is nearer to 2 (Table 6).

As TDS was found to be correlated significantly with most of the other parameters, TDS was neglected and again the regression analysis was executed in order to develop a new equation. So TDS is dropped and re calculated the WWQI and again fitted the regression model, and got the regression equation as follows with $98.2 \%$ of accuracy (Table 9).

$$
\begin{gathered}
\mathrm{Y}_{\text {Estimated }}=0.4595+0.000457 \mathrm{X}_{1}+0.002464 \mathrm{X}_{2}+0.000527 \\
\mathrm{X}_{3}+0.000141 \mathrm{X}_{4}-0.0412 \mathrm{X}_{5}(\text { Table } 8)
\end{gathered}
$$

Where $\mathrm{Y}=$ WWQI after dropping TDS, $\mathrm{X}_{1}=\mathrm{SS}, \mathrm{X}_{2}=\mathrm{BOD}$, $\mathrm{X}_{3}=\mathrm{COD}, \mathrm{X}_{4}=\mathrm{Cl}$, and $\mathrm{X}_{5}=\mathrm{DO}$

Table 8: Coefficients for Regression Analysis (b)

\begin{tabular}{|c|c|c|c|c|}
\hline & Coefficients & Standard Error & $\boldsymbol{t}$ Stat & $\boldsymbol{P}$-value \\
\hline Constant & 0.459523038 & 0.026050707 & 17.63956079 & $1.79428 \mathrm{E}-29$ \\
\hline SS & 0.000456715 & 0.00015666 & 2.915317416 & 0.004593801 \\
\hline BOD & 0.002464727 & 0.000379976 & 6.486540962 & $6.48043 \mathrm{E}-09$ \\
\hline COD & 0.000527356 & $7.84664 \mathrm{E}-05$ & 6.720784388 & $2.32032 \mathrm{E}-09$ \\
\hline Cl & 0.000140821 & $3.84823 \mathrm{E}-05$ & 3.659358498 & 0.000448766 \\
\hline DO & -0.041114604 & 0.003046481 & -13.49576953 & $1.99668 \mathrm{E}-22$ \\
\hline
\end{tabular}

Table 9: Model Summary (b)

\begin{tabular}{|c|c|c|c|c|c|}
\hline Model & $\mathrm{R}$ & $\mathrm{R}$ Square & Adjusted R Square & Std. Error of the Estimate & Durbin-Watson \\
\hline 1 & .993 & .986 & .986 & .00638 & 1.954 \\
\hline
\end{tabular}

Table 10: ANOVA (b)

\begin{tabular}{|c|l|c|c|c|c|c|}
\hline \multicolumn{2}{|c|}{ Model } & Sum of Squares & $\mathrm{df}$ & Mean Square & F & Sig. \\
\hline \multirow{3}{*}{2} & Regression & .240 & 5 & .048 & 1180.260 & $.000^{\mathrm{b}}$ \\
\cline { 2 - 8 } & Residual & .003 & 81 & .000 & & \\
\cline { 2 - 8 } & Total & .244 & 86 & & & \\
\hline
\end{tabular}

This model is fitted significantly as $F=1180.260$ ( $p$-value: 0.000) (Table 10), also root mean square error (RMSE) is 0.000. Each parameter has significant effect on WWQI (Table $8)$. This model is not having problem of auto correlation as Durbin-Watson test statistic is 1.954 which is nearer to 2 (Table 9).

Now DO depends on the strength of wastewater i.e. WWQI. As the value of WWQI is close to 1, poor is the quality of treated wastewater and measured DO will be less in quantity and for the WWQI nearer to zero, quality of wastewater is very good for reuse and the DO will be more. In order to predict $\mathrm{BOD}$, regression equation can be fitted with BOD as explanatory variable and DO as dependent variable. Following equation was developed to calculate BOD.

Y Estimated $=29.182+0.951 \mathrm{X} 1+\mathrm{e}($ Table 11$)$

Where $\mathrm{Y}=\mathrm{BOD}, \mathrm{X} 1=\mathrm{DO}$ and $\mathrm{e}$ is error term. This model is fitted significantly as $\mathrm{F}=356.781$ ( $\mathrm{p}$-value: 0.000 ) (Table 13), also root mean square error (RMSE) is 0.000 with $96.9 \%$ of accuracy (Table 12). 
Table 11: Coefficients for Regression Analysis (c)

\begin{tabular}{|c|c|c|c|c|c|c|}
\hline \multicolumn{2}{|c|}{ Model } & \multicolumn{2}{|c|}{ Unstandardized Coefficients } & \multirow{2}{*}{$\begin{array}{c}\begin{array}{c}\text { Standardized } \\
\text { Coefficients }\end{array} \\
\text { Beta }\end{array}$} & \multirow[t]{2}{*}{$\mathrm{t}$} & \multirow[t]{2}{*}{ Sig. } \\
\hline & & B & Std. Error & & & \\
\hline \multirow[t]{2}{*}{1} & (Constant) & 29.182 & .951 & & 30.698 & .000 \\
\hline & DO & $-4.966-$ & .273 & $-.892-$ & $-18.203-$ & .000 \\
\hline
\end{tabular}

Table 12: Model Summary (c)

\begin{tabular}{|c|c|c|c|c|}
\hline Model & R & R Square & Adjusted R Square & Std. Error of the Estimate \\
\hline 3 & $.985(\mathrm{a})$ & .969 & .969 & 4.18460 \\
\hline
\end{tabular}

Table 13: ANOVA (c)

\begin{tabular}{|l|l|c|c|c|c|c|}
\hline \multicolumn{2}{|l|}{ Model } & Sum of Squares & df & Mean Square & F & Sig. \\
\hline \multirow{3}{*}{1} & Regression & 1237.090 & 1 & 1237.090 & 356.781 & $.000^{\text {a }}$ \\
\cline { 2 - 7 } & Residual & 294.726 & 85 & 3.467 & & \\
\cline { 2 - 7 } & Total & 1531.816 & 86 & & & \\
\hline
\end{tabular}

a. Predictors: (Constant), DO

b. Dependent Variable: BOD

Similarly the WWQI can be estimated from regression equation fitted with WWQI as explanatory variable and DO as dependent variable. Following equation was developed to calculate WWQI.

Y Estimated $=0.672-0.068 \mathrm{X} 1+\mathrm{e}($ Table 14$)$

Where $\mathrm{Y}=\mathrm{WWQI}, \mathrm{X} 1=\mathrm{DO}$ and $\mathrm{e}$ is error term.

Table 14: Coefficients for Regression Analysis (d)

\begin{tabular}{|c|c|c|c|c|c|}
\hline \multirow{2}{*}{ Model } & \multicolumn{2}{|c|}{ Unstandardized Coefficients } & Standardized Coefficients & \multirow{2}{*}{ Sig. } \\
\cline { 2 - 6 } & B & Std. Error & Beta & 150.041 & .000 \\
\hline \multirow{2}{*}{1} & (Constant) & .672 & .004 & & $-.985-$ \\
\cline { 2 - 6 } & DO & -.068 & .001 & $-52.922-$ & .000 \\
\hline
\end{tabular}

a. Dependent Variable: WWQI

Table 15: Model Summary (d)

\begin{tabular}{|c|c|c|c|c|c|c|}
\hline Model & $\mathrm{R}$ & $\mathrm{R}$ Square & Adjusted R Square & Std. Error of the Estimate & R Square Change & Durbin-Watson \\
\hline 1 & $.985^{\mathrm{a}}$ & .971 & .970 & .0091875 & .971 & 1.608 \\
\hline
\end{tabular}


Table 16: ANOVA (c)

\begin{tabular}{|c|c|c|c|c|c|c|}
\hline \multicolumn{2}{|c|}{ Model } & Sum of Squares & df & Mean Square & F & Sig. \\
\hline \multirow{4}{*}{1} & Regression & .236 & 1 & .236 & 2800.788 & $.000^{\mathrm{a}}$ \\
\cline { 2 - 7 } & Residual & .007 & 85 & .000 & \\
\cline { 2 - 7 } & Total & .244 & 86 & & \\
\end{tabular}

a. Predictors: (Constant), DO

b. Dependent Variable: WWQI

The graphical comparison for WWQI developed by MCDM Method and both regression equations is shown in Figure 3.
The Figure 3shows that the result slightly deviates with TDS and it almost matches without TDS.

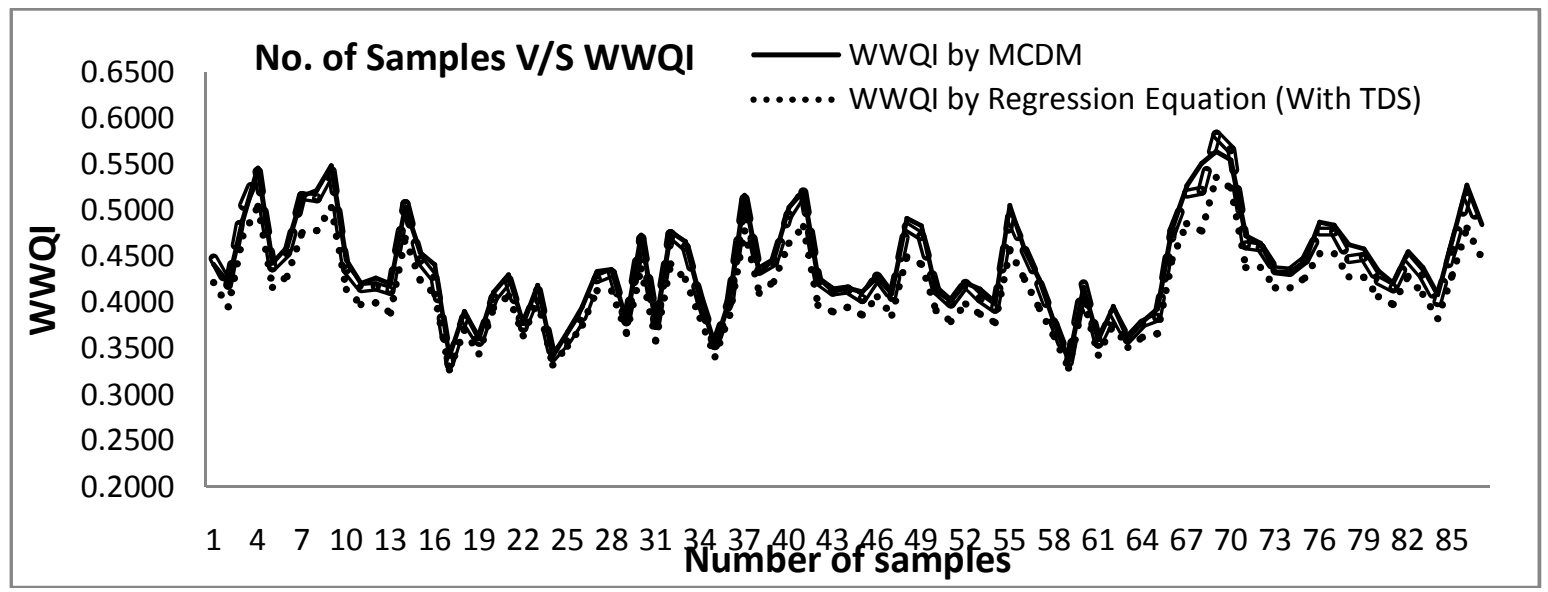

Fig 3 Comparison in WWQI calculated by MCDM method and two regression equations

Figure 4 shows the comparison between BOD and BOD Estimated from regression equation and Figure 5 shows the
Comparisonbetween WWQIand WWQI Estimated.

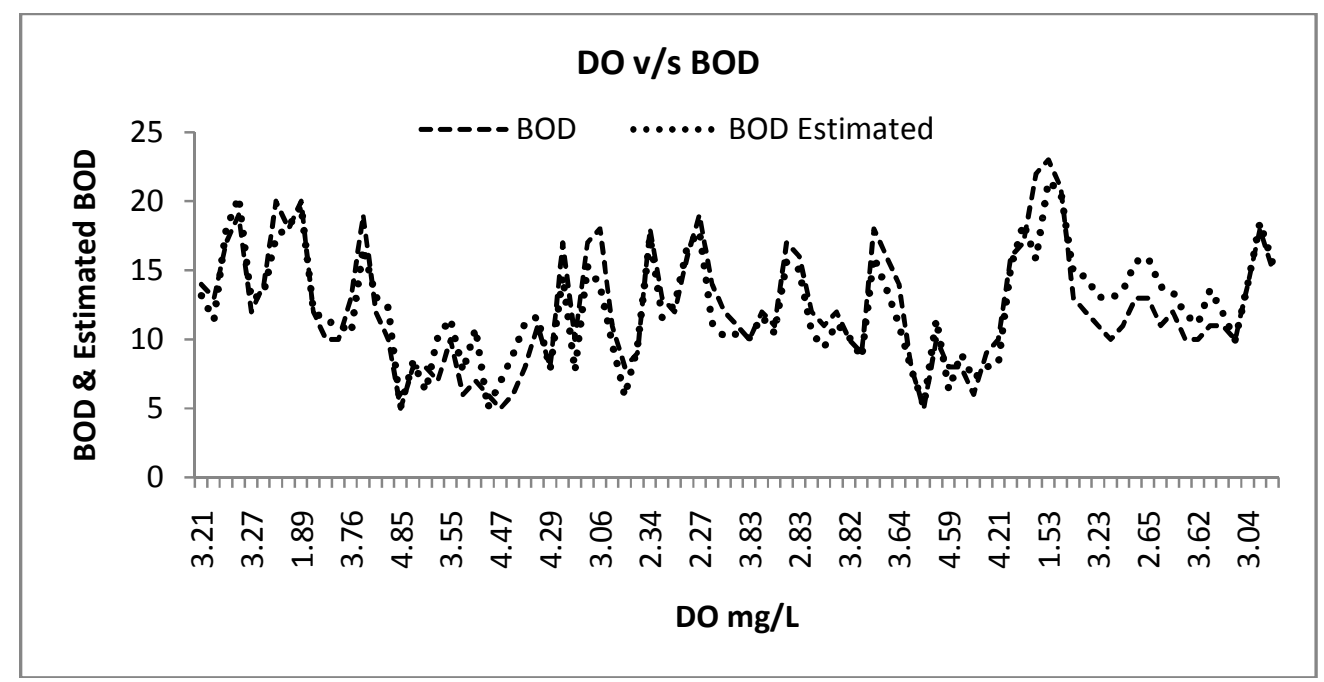

Figure 4 shows the comparison between BOD and BOD Estimated 


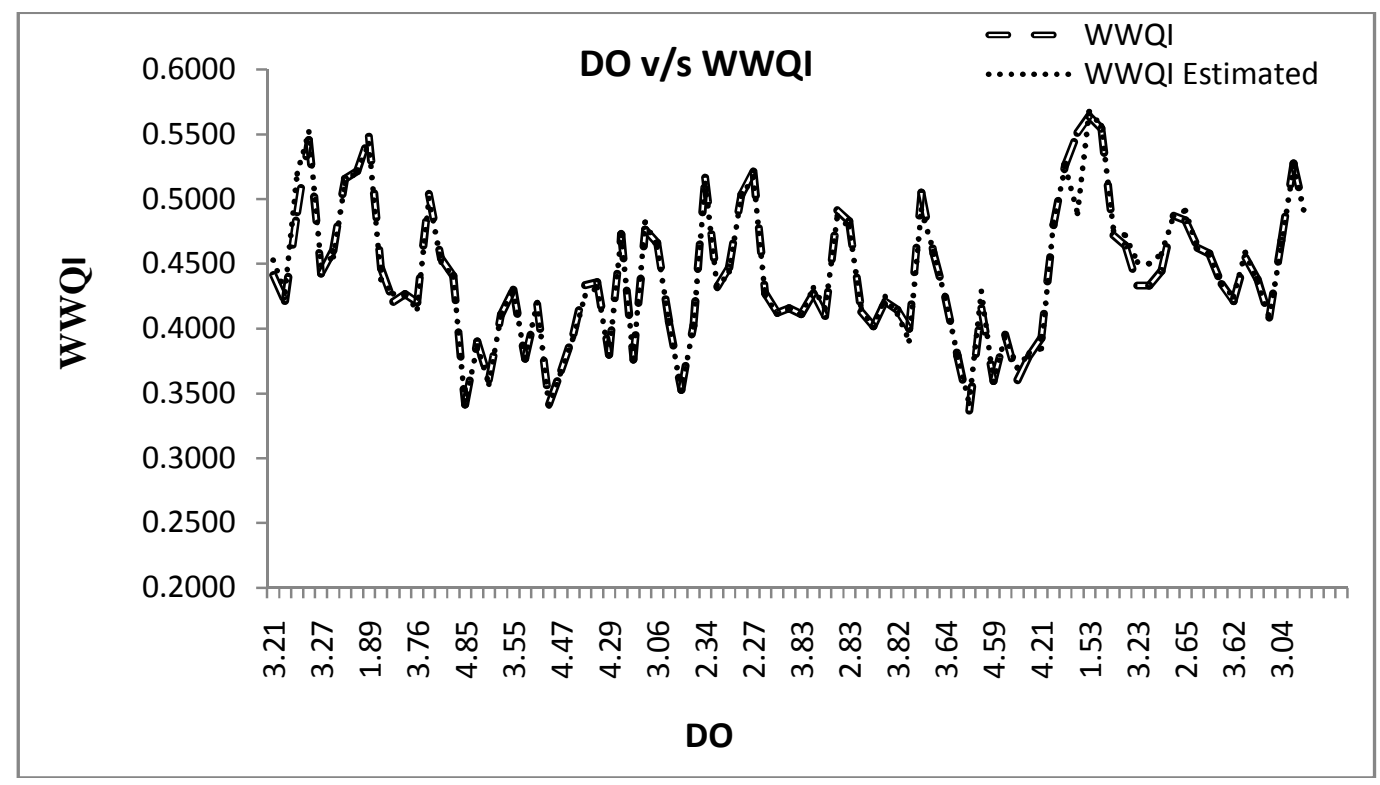

Fig 5 shows the comparison between WWQI and WWQI ${ }_{\text {Estimated. }}$

\section{CONCLUSIONS}

First WWQI was found and later the correlation for the interrelation between different parameters and their correlation with WWQI was determined with help of SPSS. From this analysis WWQI is significantly correlated with TDS, SS, $\mathrm{BOD}, \mathrm{COD}, \mathrm{Cl}$ and $\mathrm{DO}$ which means that out of these nine parameters, only Six parameters are responsible for the deviation or change in the values of WWQI. Also it was found that TDS, SS, BOD, COD, $\mathrm{Cl}$ and DO were significantly correlated with WWQI at 0.01 Level.

When 6 parameters were considered and regression equation was developed, it was found nearly $98.2 \%$ accurate.

$\mathrm{Y}$ Estimated $=0.456+0.0000103 \mathrm{X} 1+0.000451 \mathrm{X} 2+$ $0.002448 \mathrm{X} 3+0.000530 \mathrm{X} 4+0.000128 \mathrm{X} 5-0.0412 \mathrm{X} 6$.

It has the standard error of 0.00642 . Now, as it has R Square > .75 , the equation is acceptable and can be applied to determine WWQI instead of performing whole tedious procedure of MCDM Method.

Further omitting TDS and considering five parameters and developed regression equation it was found $98.6 \%$ fitting with the original WWQI. The equation was like:

$\mathrm{Y}$ Estimated $=0.4595+0.000457 \mathrm{X} 1+0.002464 \mathrm{X} 2+$ $0.000527 \mathrm{X} 3+0.000141 \mathrm{X} 4-0.0412 \mathrm{X} 5$.

It has the standard error of 0.969 . Now, as it has R Square > .75 , this equation is also acceptable and can be applied to determine WWQI instead of performing whole tedious procedure of MCDM Method. But, as accuracy increases only about $0.04 \%$, we can neglect determination of TDS also which may result in considerable time saving and reduce complications in determination of WWQI.

The estimated BOD from independent variance DO for maximum, minimum and average is $25.35 \mathrm{mg} / \mathrm{L}, 2.65 \mathrm{mg} / \mathrm{L}$ and $13.56 \mathrm{mg} / \mathrm{L}$ respectively. While estimated WWQI from independent variance DO for maximum, minimum and average is $0.6212,0.3074$ and 0.4581 respectively.

Hence, instead of analyzing all 9 parameters (neglecting FC and FS) only 6 or 5 parameters can provide results with sufficient accuracy around 98-99 \%. This eliminates tedious procedure of determining and testing each and every parameter which ultimately results in considerable amount of time, chemicals and money savings. Also higher accuracy eliminates any chances of deviation form original WWQI expect shock loadings.

\section{REFERENCES}

[1] Akobundu A. N., Quality assessment of Aba River using heavy metal pollution index, Am. J. Environ. Engin., 2012, 2(1), 45-49.

[2] American public health association, (APHA). Standard methods for the examination of water and wastewaters, 2003. $\left(21^{\text {th }}\right.$ edn). Washington, DC, USA.

[3] Balteiro, L., and Romero, C., In search of a natural systems sustainability index, 2004, Ecological Economics, 49 (3), 401-405.

[4] Bharti N. and Katyal D., Water quality indices used for surface water vulnerability assessment, International Journal of Environmental Science, 2011, 2(1), 154-173. 
[5] Bordalo A. A., Teixeira R. and Wiebe W. J., A water quality index applied to an international shared river basin : The case of the Douro River, Environ. Manag., 38(1), 2006, 910-920.

[6] Chen,Y., C., Lien, H., P., Tzeng, G., H., and Yang, L., S., Fuzzy MCDM approach for selecting the best environment-watershed plan, Applied Soft Computing Journal, 2011,11(1), 265-275.

[7] Chenini I. and Khemiri S., Evaluation of ground water quality using multiple linear regression and structural equation modelling, Int.J. Environ. Sci. Tech., 2009, 6 (3), 509-519.

[8] Evangelos., $\mathrm{P}$ mastering visual basic 6, BPP Publications, New Delhi, (2000).

[9] Florence P. L., Paulraj A.,Ramachandramoorthy T., Water Quality Index and correlation study for the assessment of water quality and its parameters of YercaudAluk, Salem District, Tamil Nadu, India, Chem. Sci.Trans., 2010,1(1), 139-14.

[10] Gabrieli, R.; Divizia, M.; Donia, D.; Ruscio, V.; Bonadonna, L.; Diotallevi, C.; Villa, L.; Manzone, G.; Panà, A., Evaluation of the wastewater treatment plant of Rome airport. Water Science and Technology, 1997, vol. 35, issue 11-12. p. 193-196

[11] Hwang, C., and Yoon, K. Multiple attribute decision making - methods and applications, A state of the art survey, Springer-Verlag, Berlin. ,1981.

[12] Jamrah, A., I., Assessment of characteristics and biological treatment technologies of Jordanian wastewater, 1999, Bioprocess Engineering, 21: 331340 .

[13] Jamwal, P., Mittal, A., K. and Mouchel,J., M. Efficiency evaluation of sewage treatment plants with different technologies in Delhi, (India). 2009, Environmental Monitoring assessment,153, 293-305.

[14] Kaufman, A., and Gupta, M., M. , Fuzzy mathematical modelling in engineering and management sciences, Fuzzy Set and Systems, 1991, 43, 17-32.

[15] Klir, G., J., and Yuan, B. , Operation of fuzzy sets in: Ruspini, E. H., Bonissone, P. P. and Pedryez W., Handbook of Fuzzy Computation, Institute of Physics Publishing, Dirac House, temple Bath, Bristol , 1998.

[16] Mohammed,B , Design and Performance Evaluation of a Wastewater Treatment Unit." Australian Journal of Technology. , 2006, 9(3): 193-198 .

[17] Prati L., Pavanello R. and PesarinF.,Assessment of surface water quality by a single index of pollution, J. Wat. Res.,1971, 5(1), 74.

[18] Rastogi. G.K. and Sinha D. K., A novel approach to water quality management through correlation study, Journal of Environmental Research and Development , 2011, 5 ,(4), 1029-1035.

[19] Ravikumar, P., Liza, B., Pinto. andSomashekar, R., K., Assessment of the Efficiency of Sewage Treatment plants: A Comparative Study between NagasandraandMailasandra Sewage Treatment Plants.
2010, Kathmandu University, Journal of Science Engineering and Technology, 6(2), 115-125.

[20] Rene E. and Saidutta M. B., Prediction of Water Quality indices by regression analysis and artificial neural networks, Int. Environ. Res., 2008,2(2), 183188.

[21] Singh, D. and Robert L. K.Tiong, A fuzzy decision framework for contractor selection, 2005, Journal of Construction Engineering and Management (ASCE), 131(1), 62-70.

[22] Thirupathaiah M., Samatha C. andSammaiah C., Analysis of water quality using physico-chemical parameters in lower manair reservoir of Karimnagardistrict,Andhra Pradesh, Int. J. Environ. Sci., 2012,3(1), 172-180.

[23] Venkatesharaju K., Somashekar R. K and Prakash K. L., Study of seasonal and spatial variation in surface water quality of Cauvery River Stretch in Karnataka, J. Ecol. Nat. Environ., 2010, 2(1), 1-9.

[24] Verlicchi P, Masotti L, Galletti A. Wastewater polishing index: a tool for a rapid quality assessment of reclaimed wastewater. Environtal Monitoring and Assessment; 2011, 173(1-4):267-77. doi: 10.1007/s10661-010-1386-7. Epub 2010 Mar 9.

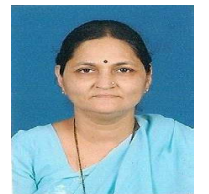

\section{BIOGRAPHIES}

Mrs. Anjali Khambete has received her bachelor's and master's from S V National Institute of Technology, Surat. Currently working as Associate Professor in the department of Civil engineering. At SVNIT, Surat. Her research interests are in the field of water and wastewater engineering. Fuzzy logic,

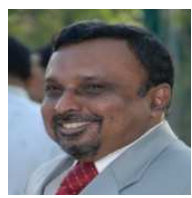

Dr. Robin Christian has received his master's and $\mathrm{PhD}$ from $\mathrm{S} \mathrm{V}$ National Institute of Technology, Surat. Currently working as Associate Professor in the department of Civil engineering. At SVN IT, Surat. His research interests are noise pollution, application of fuzzy logic in environmental field. Published many papers in international journals related to environmental engineering. 